parents. Nevertheless, it is a great deal easier to theorize about allergy than to cure it, and, while there can be no doubt that inhibitory forces exist within the organism which can check the appearance of allergy in an individual who has inherited the tendency, there is no evidence that we can direct these forces in such a way, for example, as to prevent the appearance of infantile eczema in the offspring of allergic parents. It may therefore be most practical in the long run to concentrate on the factor of protein sensitization and try to render the home environment free from the common allergens-dusts and moulds.

\section{Unsightly Bursa}

Q.-Is there any curative treatment for the pads of fat or bursae which appear round the external malleoli of middle-aged women? They are not painful but very unsightly.

A.-Treatment for this condition can be only by deep massage and elastic bandaging. There is no other satisfactory palliative measure. Curative treatment by plastic operations seems desirable only where the cosmetic result is of particular importance.

\section{Carbachol for Migraine}

Q.-Has carbachol any effect on migraine? If so, what doses should be used?

A.-Carbachol has been stated to have an effect in migraine by A. K. James in an article in this Journal (May 12, 1945, p. 663). $\mathrm{He}$ found that a patient to whom he was giving tablets of carbachol orally for a dilated colon suffered much less from attacks of migraine during the course of the treatment. He therefore tried the method in other patients, and has published results in 12 . He recommends tablets each containing $0.002 \mathrm{~g}$. (which is $2 \mathrm{mg}$. or $1 / 30 \mathrm{grain}$ ); two of these tablets are taken at once, and this dose is repeated two or three times a day. The daily dose was mostly $6 \mathrm{mg}$., but one patient was given $12 \mathrm{mg}$.

\section{Colloidal Gold (Lange) Reaction}

Q. - Can you explain why it is that in an early case of G.P.I. the cerebrospinal fluid, which is W.R.-positive and gives a marked paretic reaction with Lange's gold test, will, after being kept frozen for three weeks, give a characteristic luetic curve? I have seen this twice recently. Is it common?

A.-The colloidal gold (Lange) reaction is dependent on the presence of globulins in the cerebrospinal fluid; freezing the fluid in the refrigerator tends to "denature " the globulins and render them less soluble when the fluid is thawed. In the case of a fluid which has been frozen and then thawed this might explain the change in the gold curve. The difficulty could probably be overcome by drying the cerebrospinal fluid in the same way as serum is dried: this process apparently does not denature the globulins.

\section{Miller-Abbott Tube}

Q.-How is the Miller-Abbott tube used and what are the indications for employing it?

A.-The Miller-Abbott tube is a double-channelled narrow-bore rubber tube which is used for the relief of obstruction of the smal bowel. In some cases it also helps to locate the site of obstruction. One channel is larger than the other and is used for sucking out the contents of the stomach and intestine; the smaller channel is used for the purpose of injecting air into a rubber balloon which surrounds the distal end.

The tube should be used only for those cases of obstruction in which one can fairly exclude strangulation of the bowel, for emptying the bowel above the strangled coil will in nowise prevent supervention of gangrene. Its chief use is in cases of obstruction due to kinks and adhesions in which distension actually increases the obstruction, in cases of paralytic ileus, and perhaps in some cases of incomplete obturation-e.g., obstruction by a gall-stone.

The tube can be introduced through the mouth or nose-preferably through the nostril, which has the clearest passage. If necessary the nostril and pharynx may be sprayed with a solution of cocaine to lessen irritation. The tube is moistened and pushed gently through the nostril till it reaches the nasopharynx; the patient is then given a little water to swallow while the tube is pushed on towards the gullet. Thereafter it is carried down to the stomach by the patient's own swallowing efforts. The fact that the tube has reached the stomach may be told either by the length of tube which has been swallowed, by the nature and quantity of fluid which may be aspirated, or by inflating the little balloon and gently drawing the tube back till the balloon is stopped by the cardia. After relieving the distended stomach by aspiration of the contents the patient is told to lie on the right side with a view to encouraging the tube to pass on to the duodenum. This should take place within ten or fifteen minutes. The fact that the tube is within the duodenum can sometimes be ascertained by noting the nature and reaction of the aspirated contents; otherwise by inflating the balloon with about $30 \mathrm{c.cm}$. of air and noting the rather irregular resistance met with during inflation. When once within the small bowel, the tube with its inflated end is gradually forced along the lumen. From time to time the contents of the bowel are aspirated through the larger channel so that the bowel is emptied of air and fluid as the tube advances. Its rate of advance varies from one to two feet an hour. Ultimately the end of the tube will reach down to the site of obstruction, and the relief of distension may actually cure the condition. In cases of organic stricture the tube will stop on the proximal side of the obstruction, and either may be seen by $x$-ray screening, or a little barium emulsion may be injected through the tube and may serve to demonstrate the obstruction.

The caution must be repeated that the use of the Miller-Abbot tube will not prevent gangrene in a strangled coil of gut; in such cases it may relieve the distension of the bowel above the obstruction and so make the necessary operation more safe.

\section{LETTERS, NOTES, ETC. Venereology}

Mr. L. E. Eyres, M.A., writes from Ampleforth College, York: May a schoolmaster, with some knowledge of Latin and Greek, but none of medicine, intervene in your interesting debate on venereology, and offer the following reflections? The difficulty is enhanced by the fact that "V.D." is a violent euphemism. In itself " venereal " merely means " pertaining to the goddess of Love," and the enotion which a man feels towards the harlot who gives him gonorrhoea is certainly not love, or anything like it. In a world where spades were spades V.D. would mean, at worst, nymphomania, or its masculine counterpart. And when V.D. is shortened to "venereal" it becomes doubly euphemistic. The nuisance about euphemisms is that once they become established they deny us the use of the word or phrase in its proper sense. If I say " my mother went home yesterday" there are some tiresome people who will take me to mean that she died yesterday. Nor can I say that I have found a comfortable asylum for Aunt Susan without implying that she is insane. With a small $v$ "venus" means beauty, charm, etc. Yet if I call Miss Smith a venereal young woman she will not take it as the compliment that it is, though she will not mind my calling her fiancé a martial young man. The expression "V.D." is now firmly established, and, though it is a slander on Aphrodite, pedants must acquiesce in it. But to introduce a twofold euphemism and call it simply "venereal" would be regrettable, I think, in a scientific treatise. Aedoeology would be strictly accurate: it is a pity that it is such a hideous word. But is it really any worse than, say, gynaecology.or aitiology?

\section{War-blinded Men}

From St. Dunstan's (9-11, Park Crescent, W.1) there comes an illustrated pamphlet with an article by Sir Ian Fraser, chairman of the Executive Council, describing the work which that institution, a product of the earlier war, has done during the war just ended Work for the blinded was first thought of as limited to home handicrafts, but Sir Ian Fraser says that experience has shown that, given proper training, blinded men can operate machines in ordinary factories. St. Dunstan's has placed 120 men of the last war and 45 men of the recent war in munition and aircraft factories all over the country. Fifty St. Dunstaners of the recent war have been trained or are training as masseurs, and 47 as telephone operators, while others are following their older comrades as smallholders, poultry farmers, shopkeepers, and the like. One man has been placed as a labour manager, another as a research engineer, and a third has successfully passed his law examinations. St. Dunstan's has established homes in India and in South Africa, and it is expected that the former will prove to be a pioneer institution in the care of the blind in India. Altogether over 900 blinded Service men and women, victims of the second world war, have passed through St. Dunstan's

\section{A Missing Doctor}

Surg. Lieut.-Cmdr. A. S. PlayfaIr (Manor House, Bagdale, Whitby, Yorks) writes: I have been asked by the very anxious rela- 0 tives of the Dutch Dr. J. W. Brinkman if I could help in any way C

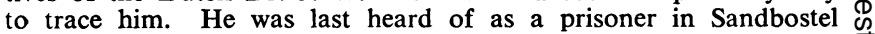
Camp in Germany in April, 1945. Apparently he fell ill with typhus fever just before the liberation, and was afterwards under the care of British Service doctors. In June his name could not be found in the list of those who had died in the camp epidemic. Other arduous attempts to trace him have failed. I should be most grateful if you could publish this, with its request for any doctor who might $\varrho$ have some information, however slight, to write to me as soon as possible.

Dr. D. G. McIntosh, referring to the letter on the erythrocyte sedimentation rate (Oct. 27, p. 584), says that owing to an oversight he omitted to add corrections to the list of references cited. The corrected references should read:

Abeles, H., and Pinner, M. (1944). Amer. Rev. Tuberc., 49, 490

Clive, F. T. (1943). Tubercie, 24, No. 4, 63.

Lancet, 1, 42

Stiehm, R. H.(1939). Amer. J. med. Sci., 197, 517. 